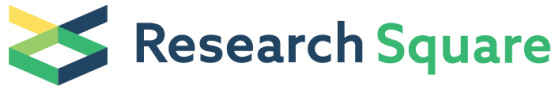 \\ Preprints are preliminary reports that have not undergone peer review. \\ They should not be considered conclusive, used to inform clinical practice, or referenced by the media as validated information.
}

\section{The costs of keeping schools open during the COVID-19 pandemic}

\author{
David Haw \\ Imperial College London \\ Giovanni Forchini \\ Imperial College London \\ Paula Christen \\ Imperial College London \\ Sumali Bajaj \\ University of Oxford \\ Alexandra Hogan \\ Imperial College London \\ Peter Winskill \\ Imperial College London \\ Marisa Miraldo \\ Imperial College London \\ Peter White \\ Imperial College London \\ Azra Ghani \\ Imperial College London \\ Neil Ferguson \\ Imperial College London \\ Peter Smith \\ University of York \\ Katharina Hauck ( $\nabla$ k.hauck@imperial.ac.uk) \\ Imperial College London https://orcid.org/0000-0003-3138-4169
}

Article

Keywords: economics, SARS-CoV-2, SEIR model, lockdown, hospital capacity, economic sectors, interdependencies, epidemiology

Posted Date: May 21st, 2021

DOI: https://doi.org/10.21203/rs.3.rs-283318/v1

License: @ (i) This work is licensed under a Creative Commons Attribution 4.0 International License. Read Full License 


\section{Abstract}

There is a trade-off between restrictions on the education sector and other economic sectors in the control of SARS-CoV-2 transmission. Here we integrate a dynamic model of SARS-CoV-2 transmission with a 63-sector economic model reflecting sectoral heterogeneity in transmission and economic interdependence between sectors. We identify control strategies which optimize economic production while keeping schools and universities operational, and constraining infections such that emergency hospital capacity is not exceeded. We estimate an economic gain of between $£ 163 \mathrm{bn}(24 \%)$ and $£ 205 \mathrm{bn}$ (31\%) for the United Kingdom compared to a blanket lockdown of non-essential activities over six months, depending on hospital capacity. Sectors identified as priorities for closures are contact-intensive, produce few crucial inputs for other sectors and/or are less economically productive. Partial closures over some months are required for retail trade, hospitality, accommodation, creative activities, arts, entertainment, and personal services including hairdressing and beauty treatments under most scenarios.

\section{Introduction}

Closures of schools, universities, and workplaces are a key non-pharmaceutical intervention (NPI) in the control of the COVID-19 pandemic, ${ }^{1,2}$ and were implemented by many countries in the first half of 2020 when infections were rising rapidly. By mid-2020, UNESCO ${ }^{3}$ estimated that around $60 \%$ of the world's students had their education disrupted by national closures of educational institutions during the pandemic. Even short periods of missed education can have grave consequences for educational development, ${ }^{4-6}$ reduce lifetime earning potential, ${ }^{7}$ and damage social and psychological development of children and young adults. ${ }^{8}$ School closures are also associated with lost income and productivity of carers who cannot work because of childcare responsibilities. ${ }^{9}$

The high economic and social costs of school and university closures have led most countries to re-start education activities in the second half of $2020,{ }^{10}$ even if this increases SARS-CoV-2 transmissions and puts heavy pressure on health services. ${ }^{11}$ The New York Times commented that France and many other European nations are managing to keep infections under control while keeping schools open. ${ }^{12}$ The Prime Minister of the United Kingdom stated in December that children must be kept in schools, even if that puts pressure on the hospitality sector and other parts of the economy. ${ }^{13}$ To maintain control, European countries have to tighten NPIs in other areas of society, most notably through closure of businesses deemed non-essential for day-to-day life. Lockdowns of non-essential businesses are also associated with high economic and social costs, ${ }^{14-17}$ and they are a crude lever if implemented as a blanket policy across the whole economy. Economic sectors differ greatly in the infection risk that they pose to both workers and consumers, in their potential to implement effective social distancing measures, and in the contribution they make to Gross Domestic Product (GDP). It is vital to determine how lockdowns can be finetuned to prevent health services from being overwhelmed, whilst allowing educational institutions to stay open and minimizing economic costs associated with business closures.

Conventional GDP measures do not fully capture the benefits of health and education services. ${ }^{18}$ We therefore present here a closure strategy which identifies an optimal six-month trajectory of selective opening and closing of 63 sectors while keeping educational institutions operational and infections under control. We maximize GDP while limiting the spread of SARS-CoV-2 over six months, with periodic decisions on economic configurations - the extent to which each sector is open. We have hardly any empirical evidence on how to optimally design lockdown policies during pandemics. Our findings are generated by a modelling study that necessarily rests on many assumptions, but they provide urgently needed guidance to policy makers on how to design policies that balance key societal objectives.

\section{Methods}

In our model we assume that relatively contact-light sectors which employ fewer workers carry fewer infections back into the community when they are open compared to more contact-intensive sectors with more workers (see Supplement for a detailed description of the model). Partial or full opening and closing of sectors are assumed to give rise to proportionate changes in the sector's active workforce, community transmission, and the associated impact on disease transmission. We then use the model to identify the set of sector closures over time that maximizes GDP, whilst keeping the education sector operational and containing daily hospital occupancy of COVID-19 patients within the maximum spare emergency hospital capacity $\left(\mathrm{H}_{\text {max }}\right)$. We consider three different assumptions for $\mathrm{H}_{\max }$ (either 12,000,18,000, or 24,000 beds available, noting that at the peak in April 202018,000 COVID-19 patients occupied beds). We further constrain the effective reproductive number $R_{t}$ to be at or below 1 at the end of six months, ensuring that residual infections do not cause a rapid epidemic just beyond the intervention period.

Our strategy does not necessarily prioritize the sectors of the economy that contribute most to GDP relative to the spread of infection. Instead, it respects interdependencies between sectors, all of which rely, to some extent, on inputs from other sectors to produce their final and intermediate outputs; a sector that is nominally opened may not be able to function properly if its supply chain is interrupted. ${ }^{19,20}$ We obtained data on interdependencies between all 63 sectors from the most recent United Kingdom (UK) Input-Output (IO) table for 2016, ${ }^{21}$ see table S1 for education. We use recent data on the workforce, ${ }^{22}$ and on those working-from-home. ${ }^{23}$ We specify a lower bound to production, given by the economic configuration that allows essential services to operate. Specifically, economic activity is sustained throughout to at least $80 \%$ (healthcare $100 \%$ ) of those observed during the UK's first lockdown in March-May 2020 , to allow for uncertainty regarding the exact values and changes in production processes. ${ }^{24,25}$ The upper bound is given by the level of pre-pandemic production and assumes that the demand for goods and services does not exceed pre-pandemic levels. The chosen closure of sectors under optimal solutions is influenced by at least five sector characteristics and their interplay: the size of workforce, workplace contact rates, effect on community contact rates, GDP contribution and interdependence with other sectors.

We use a deterministic Susceptible-Exposed-Infectious-Removed (SEIR) model of SARS-CoV-2 transmission to project the spread of infection in the workplace, the education sector, households and the community as sectors are opened and closed to varying degrees. The SEIR model accommodates sectoral 
heterogeneity in risks of infection via three contact matrices: worker-to-worker, community, and consumer-to-worker. Community contacts occur with respect to four age groups: 0-4, 5-19, 20-64 and 65+. This includes contacts made in and between households, outside, in education institutions, on public transport, and in hospitality venues. All working-age adults, whether actively working or not, are subject to contacts in the community. Community contact in education is estimated separately for age groups 0-4 and 5-19. Contacts on public transport are estimated by sector and are reduced by sector-specific proportions of homeworkers. We incorporate age-heterogeneity in community contacts occurring in the hospitality sector, whilst education, transport and hospitality-related contact rates are proportional to the extent of sector opening and are also age-dependent.

We calibrate the model via a least-squares fit by comparison with English hospital occupancy data from $20^{\text {th }}$ March to $30^{\text {th }}$ June 2020 by varying four parameters: ${ }^{26}$ the basic reproductive number $\mathrm{R}_{0}$; effectiveness of the UK's first lockdown captured by a parameter $\delta_{L D}$; epidemic start time and lockdown onset. Transmissibility is calculated from the fitted basic reproductive number $\mathrm{R}_{0}$ and pre-lockdown contact patterns using the next-generation eigenvalue method. ${ }^{27}$ Worker-to-worker contact rates are derived from a survey conducted in 2012 in France, ${ }^{28}$ and all other parameters are obtained from a separate epidemiological model fitted to UK data, ${ }^{29}$ see table S2. A scalar multiplier $\delta$ is used to capture the post-lockdown dampening impact of NPIs and individuals' behavior on transmissions as represented by $\mathrm{R}_{\mathrm{t}}$, capturing the combined effect of NPIs (other than closures) that are difficult to estimate empirically, including social distancing in social and work environments, facemasks, testing-and-tracing, shielding of the vulnerable, travel restrictions, and limits to social gatherings. The fitted value of $\delta_{\mathrm{LD}}$ over the first lockdown represents the lower bound (optimistic) estimate of $\delta$. For forward projections, we adjust $\delta$ to reflect less stringent NPIs and weaker adherence.

\section{Modelling Scenarios}

We maximize GDP while containing the spread of SARS-CoV-2 over six months, with bimonthly decisions on economic configurations from $1^{\text {st }}$ September 2020. We incorporate five types of constraints: (a) interdependencies of supply and demand between sectors; (b) in each sector, economic activity is sustained throughout to at least $80 \%$ of lockdown values (healthcare $100 \%$ ); (c) the demand for goods and services does not exceed pre-pandemic levels; (d) hospital occupancy remains within capacity $\mathrm{H}_{\max }$ throughout the intervention period; (e) at the end of the intervention period.

We then calculate GDP, total disease incidence, and hospital occupancy for five scenarios:

- Scenario A (GDP max): Maximize GDP subject to the constraints a) to e) where education, like any other sector, may be fully or partly closed;

- Scenario B (education open): Maximize GDP as in scenario A, but the education sector remains open at or above $80 \%$ of pre-pandemic level (less than $100 \%$ to account for NPIs such as online teaching at universities);

- Scenario LDA (lockdown): lockdown of all sectors (education included) at the levels of productions observed during the first lockdown. Inventories are increased or decreased to support these levels of production. Scenario LDA results in the lowest attainable infections at high economic costs, and yields lower bounds on infections and GDP;

- Scenario LDB (lockdown except education): as in LDA, except that the education sector remains operational at $80 \%$;

- Scenario FO (fully open): all sectors are fully open for six months. The hospitalization (d) and epidemiological (e) constraints are disregarded and NPIs and voluntary behaviour changes are captured by $\delta$. Scenario FO results in the greatest GDP but at the cost of high infections and deaths; it yields upper bounds on infections and GDP.

Outcomes from scenarios A and B provide the schedule of sector closures that maximizes GDP, subject to the respective constraints, whilst LDA, LDB and FO provide benchmark scenarios. We use the 'Global search' with derivative-based base algorithm 'fmincon' in MATLAB's 'global optimization' toolbox for the optimization.

\section{Results}

The strategy that maximizes GDP while keeping infections within constraints (Scenario A) allows the potential closure of all economic sectors, including the education sector. If emergency hospital capacity for COVID-19 patients is constrained at $H_{\max }=18,000$, the optimal solution lets infections increase in September and October, then from November imposes more stringent economic configurations to remain within the epidemiological constraints (Figure $1 \mathrm{~A}$, figures $\mathrm{S} 1 \mathrm{~A} \mathrm{H}_{\max }=12,000, \mathrm{~S} 2 \mathrm{~A} \mathrm{H}_{\max }=24,000$ ). This strategy of GDP maximization results solely in the closure of the education sector (Figures 1B, S1B, S2B), with activity at $93 \%$ of pre-pandemic activity in September-October, $54 \%$ in November-December and $76 \%$ in January-February (Tab. S3), assuming $\mathrm{H}_{\max }=18,000$. If $\mathrm{H}_{\max }=12,000$, then the education sector needs to close more $(83 \%, 51 \%, 65 \%)$. If $\mathrm{H}_{\max }=24,000$ then closure is only required in NovemberDecember (56\%) and January-February (86\%). Other sectors including accommodation \& food service activities (which includes hotels, restaurants, cafes, and pubs) can stay open under any $\mathrm{H}_{\max }$. Educational activities are likely chosen for closure because they contribute to transmission but have relatively little impact on short-term GDP as measured in national accounts. Our analysis considers economic production over six months, and not any longer-term economic benefits of keeping schools and universities open which are likely substantial.

The GDP achieved by Scenario $A$ is $£ 877 b n$ over six months $\left(H_{\max }=18,000\right.$, figure $3 A$ ), higher than the $£ 660$ bn of a blanket lockdown (Scenario LDA), but lower than the $£ 889 \mathrm{bn}$ achieved with a fully open economy (Scenario FO). However, Scenario FO results in high incidence and deaths. Scenario FO also means that around 68,000 COVID-19 patients would require hospital treatment at the projected peak in January 2021, compared to 18,000 patients under Scenario A.

Optimizing GDP while keeping education activities operational 
Scenario LDB requires all sectors to close at levels observed during the first lockdown except the education sector, which would operate at $80 \%$ of prepandemic activity. LDB would keep maximum hospital occupancy at around 10,000 at the peak (Figure 3B), 56\% of peak occupancy albeit not as low as LDA that allows the education sector to close as other sectors (Figure $3 \mathrm{~A}$ ). This is because expanding the activity of the education sector increases transmission.

Scenario B seeks out a differentiated sectoral closure strategy that maximizes GDP, and therefore results in less economic loss than LDB, while requiring education to remain $80 \%$ open. Under this scenario, infections (hospital occupancy and deaths) rise gradually between September-December to the hospital constraint (Figures $2 \mathrm{H}_{\max }=18,000$, S3 $\mathrm{H}_{\max }=12,000, \mathrm{~S} 4 \mathrm{H}_{\mathrm{max}}=24,000$ ), and then more stringent economic configurations are imposed in January and February to achieve the constraint on $\mathrm{R}_{t}$ at the end of the intervention period. If $\mathrm{H}_{\max }=18,000$, the sectors targeted for closure are creative, arts \& entertainment (47\% November-December, 39\% January-February, Table S4), sports, amusement \& recreation (39\% November-February), membership organizations (44\% September-October, $40 \%$ November-February) and other personal services, which includes hairdressing and beauty treatments (40\% November-February). In January-February, retail and accommodation \& food services need to close at levels of $89 \%$ and $78 \%$, respectively. If $\mathrm{H}_{\text {max }}=12,000$, additional closures are required in November and December, including accommodation \& food services (78\%), and retail (91\%). From January onwards, accommodation \& food services and retail need to close substantially (35\% and $52 \%$ ). If $\mathrm{H}_{\max }=24,000$, fewer closures are required and retail, accommodation \& food, and the arts can stay (nearly) fully open, while some of the other sectors including sports \& recreation are still required to partially close.

The economic output achieved following a strategy that optimizes GDP while the education sector is operational is $£ 863 \mathrm{bn}$ over six months $\left(\mathrm{H}_{\mathrm{max}}=18,000\right.$, Figure 3B, Table S5 GVA losses), a gain of $£ 193 \mathrm{bn}(29 \%)$ over the $£ 670 \mathrm{bn}$ associated with a blanket lockdown of all sectors except education (Scenario LDB). The gain would be $£ 163 \mathrm{bn}(24 \%)$ at $\mathrm{H}_{\max }=12,000$, and $£ 205 \mathrm{bn}(31 \%)$ at $\mathrm{H}_{\max }=24,000$. There is a GDP loss associated with the 'education open' scenarios $B$ compared to the 'GDP-maximizing' scenarios A (Figures 3A and 3B). The difference between the two reflects the GDP losses associated with keeping educational services active, which amount to $£ 14 \mathrm{bn}$ ( $£ 877 \mathrm{bn}-£ 863 \mathrm{bn}$ ) for $\mathrm{H}_{\max }=18,000$. The loss between Scenarios $A$ and $B$ is significantly higher at $£ 40 \mathrm{bn}$ if $H_{\max }=12,000$, and lower at $£ 5 b n$ if $H_{\max }=24,000$. This loss occurs because forcing the education sector open requires the closure of other sectors that make greater nominal GVA contributions, to compensate for the increase in transmissions caused by the education sector.

\section{The role of hospital capacity}

Hospital capacity has an important role to play in the trade-off between the closure of the education and other sectors. The optimal solution under Scenario A keeps occupancy at the maximum over 3 months (December-February), while it reaches the maximum for only one month (February) under Scenario B. This has very different implications for hospitals, with total bed days over the intervention period varying between $2.3 \mathrm{~m}(\mathrm{~A})$ and $1.9 \mathrm{~m}$ (B, Table S6). Sector closures can be less stringent if decision makers are prepared to let the level of infections (and hospitalizations and deaths) increase, and if they invest in an expansion of emergency hospital capacity. The gain in GDP for Scenario B when hospital capacity is increased from 12,000 to 18,000 is $£ 30$ bn over six months, and $£ 12 \mathrm{bn}$ for an increase from 18,000 to 24,000 (Figure $3 B$, Table S5). This gain occurs because the increase in hospital capacity by 6,000 beds allows for a more open economy (Figures S3B, 2B, S4B). Over the first lockdown, the UK managed to increase capacity to 18,000 beds by cancelling many elective surgeries, using private hospital capacity, deploying retired medical and nursing staff, constructing field hospitals and re-organizing care. Such interventions are not costless. Increasing capacity to 24,000 beds would require creating additional hospital capacity and most likely rationing healthcare to patients requiring lifesaving intensive hospital care.

\section{Quantifying the loss of Gross Value Added by sector}

We can quantify the GVA loss across the economic sectors that require partial closure under Scenario B compared to FO (fully open economy). Given its relatively high contribution to transmission compared to GVA, the education sector would operate at $80 \%$ under any $\mathrm{H}_{\text {max }}$. For the other sectors, there are gains associated with increasing hospital capacity for Scenarios B (Figure 4, Table S5). If $H_{\max }=12,000$, the GVA loss for accommodation \& food services amount to about $£ 9.2 \mathrm{bn}$, for retail about $£ 8.3 \mathrm{bn}$, personal services about $£ 5.4 \mathrm{bn}$, and for arts about $£ 4.9 \mathrm{bn}$. However, if hospital capacity is increased to $H_{\text {max }}=24,000$, there would be no GVA loss for accommodation \& food and retail, and losses of less than $£ 2$ bn each for the other sectors. If we allow hospitalizations and infections to increase there will be more deaths, which of course are of central importance to decision makers but which we do not calculate as part of this study. Instead, they are implicit in the level of hospital capacity chosen by decision-makers.

\section{Sensitivity analyses}

The projections from all scenarios rest on the assumption that other NPIs are relatively stringent, i.e. that interventions such as wearing facemasks, social distancing, reduced mixing of households, self-isolation, and others are implemented and well adhered to. The fitted value of $\delta$ is 0.54 , which reflects the reduction in $R_{t}$ achieved by NPIs over the first lockdown. For all scenarios, we allow for about $11 \%$ less stringency in NPIs in the period after May 2020 by setting $\delta=0.6$. We find that small increases in $\delta$ ranging from 0.61 to 0.64 for Scenario $B\left(H_{\max }=18,000\right)$ result in much stricter closures required to keep within the epidemiological constraints (Tabs. S4 versus S7), and a substantial associated GVA loss (Figure 5, Table S5). Weak NPIs translate into economic losses because stricter closures are required to keep within hospital capacity. For $\delta=0.64$, sectors with high GVA losses are retail ( $£ 21 \mathrm{bn}$ ), accommodation \& food services ( $£ 26 \mathrm{bn})$, and 'human health activities' ( $£ 20 \mathrm{bn})$, compared to Scenario FO. There is no feasible solution for $\delta=0.65$ if hospital occupancy is constrained at 18,000 or below. This demonstrates that it is impossible to keep the economy even minimally operational and maximum hospital occupancy at 18,000 if there is weak adherence to NPIs. Effectively, a society that accepts more stringent NPIs is rewarded with a higher GDP and fewer infections. There is effectively a four-way trade-off between GDP, infections (and deaths), hospital capacity and social liberties.

The projections are also sensitive to assumptions on contact rates in the community and the education sector (Figure S5). We varied contact rates by $5 \%$ standard deviation around their sector-specific means assuming contact rates are independently and normally distributed. We find that much of the uncertainty in projected hospital occupancy arises from contact rates in the community and education sectors, rather than the other economic sectors. 
At baseline, we assume that the proportion of workers homeworking stays constant at sector-specific values observed over the first lockdown. If we decrease these proportions to $20 \%$ fewer workers homeworking (Figure S6), hospital occupancy increases from a maximum peak occupancy of 18,000 to over 25,000 (Scenario B) and 28,000 (Scenario A).

Children may be less susceptible to infection than adults ${ }^{30-32}$ though evidence is conflicting. ${ }^{33,34}$ We evaluated the outcomes for scenario $B\left(H_{\text {max }}=18,000\right)$ if children under the age of 16 have a $50 \%$ lower susceptibility to infection than adults. After refitting the model, we find that schools make a somewhat lower contribution to transmission dynamics (Fig S7). Some economic sectors therefore need to close more strictly at a greater loss to GVA compared to the assumption of equal susceptibility, although the sectors recommended for closure are the same.

Lastly, we evaluated outcomes when changes to the economic configuration are allowed every month instead of two months (Figure S8). The reduction in GVA loss is modest ( $£ 487$ million, table S5), and may not justify the upheaval associated with more frequent changes in policy.

\section{Conclusion}

We examine the extent to which economic activity can be sustained whilst educational institutions are kept open. If a differentiated sectoral closure strategy is followed, whereby certain economic sectors are partially closed over a six-month period, a GDP gain of between $£ 163 \mathrm{bn}(24 \%)$ and $£ 205 \mathrm{bn}$ (31\%) over six months can be secured (depending on spare hospital capacity) compared to a blanket lockdown of all non-essential services. Differentiated sectoral closures that keep hospital occupancy at a set maximum (between 12,000 and 24,000) throughout the period are compared with a fully open economy that is projected to cause about 68,000 COVID-19 patients requiring hospital care at its peak. Activities that require partial closure in various months over autumn and winter 2020/21 are accommodation \& food services including restaurants and bars, retail, creative and arts, entertainment, sports, amusement, recreation, and activities of membership organizations. To achieve the same outcomes, sectoral closures need to be much stricter if adherence to other NPIs such as social distancing is weak. Decision makers can reoptimize for a new intervention period before the end of six months if objectives change or new data become available.

A few studies focus on the trade-off between economic and public health impact of COVID-19 and compare optimal control strategies by economic sector. ${ }^{19,20,35-38}$ Most studies simplify the economy by allocating sectors into two categories, with the exception of two studies ${ }^{19,20}$ which model interdependencies. All past studies specify simplified epidemiological models that do not consider latent period, asymptomatic infection, and differences in severity which are important for realistic projections. All but two models ${ }^{35,36}$ are theoretical and not fitted to the actual pandemic trajectory, limiting their usefulness for informing policy. And while all studies investigate combined epidemiological and economic effects of lockdown policies, they fall short of calculating impact on GVA by sector. In contrast, we developed a transmission model that is calibrated to the pandemic in the UK and differentiated by 63 economic sectors, and that poses the decision makers' problem as a constrained optimization of economic output. This allows us to give numerical outputs that can guide decisions about which sectors to open, and to what extent.

Our analysis has important limitations. We use contact data classified by economic sector of employment. ${ }^{28}$ Although the survey is likely to be representative of many high-income countries, such data would ideally be tailored directly to the country and the detailed sectors under scrutiny. Additionally, the sector in which the survey respondent is employed is reported only at a high level and does not give further information on what type of work the individual performs. There are large variations in physical proximity by occupation type. ${ }^{39}$

The most recent available 10 table is from 2016 and does not reflect recent changes in the economy. In line with usual IO methodology, we assume Leontief production functions with constant returns to scale. ${ }^{40}$ With heterogeneous sectors it will always be the case that partial opening of a sector may be able to focus on subsectors that are highly productive or have low reliance on inputs from other sectors that remain closed. However, policymakers may find it difficult to formulate granular opening/closure policies focusing on economic activities within sectors and instead be forced towards blanket sectoral policies. A further concern is that - with constraints on supplies - some producers may change to alternative suppliers. However, relatively fixed production processes mean that there is likely to be limited scope for changing the sector in which the supplies are produced. Producers may instead seek to solve supply chain problems by importing inputs for which there are domestic shortages. We have built in certain flexibility in production processes by allowing some tolerance in maximum and minimum levels of economic activity.

We make no allowance for changes in prices or demand for final products. To some extent, if demand changes for a sector's produce are expected and can be quantified, this can be incorporated by imposing an exogenous change to the relevant economic constraint. We do not model the effect of vaccinations, because they are unlikely to significantly impact transmission of SARS-CoV-2 within our intervention horizon. We also do not model the impact of the new SARS-CoV-2 lineage B.1.1.7 on transmissibility as evidence is only emerging now. ${ }^{29}$ Vaccinations and new variants will be considered in future applications of DAEDALUS. Lastly and importantly, we have made only rudimentary efforts to adjust for NPIs put in place to reduce transmission risk and voluntary behavior change. The major challenge is identifying the likely nature and magnitude of changes in demand, NPIs and behavior in the absence of available data, although estimates may be forthcoming as evidence from countries' experiences becomes available.

Our study attempts to minimize the deleterious effects to the broader economy of protecting education and health services, a policy trade-off that is being considered worldwide. While the world is waiting for effective vaccines deployed at scale, the policy challenge will be how to keep educational institutions open, the economy as open as possible, and the pandemic controlled so that health services are not overwhelmed. We need novel economic models that incorporate transmission dynamics as constraints, ${ }^{41}$ such as the one we present here. While the precise monthly economic configurations identified by our study are sensitive to the stringency of other NPIs, the recommended priority list of sectors to keep open and close proved robust to sensitivity analyses. Faced with a recession of historic magnitude, we need to quantify difficult trade-offs to minimize societal harm. 


\section{Declarations}

\section{Acknowledgements:}

DH, GF, PC, SB, ABH, PW, ACG, NMF and KH were supported by the NIHR HPRU in Modelling and Health Economics, a partnership between Public Health England, Imperial College London and LSHTM (grant code NIHR200908). DH, GF, PC, SB, ABH, PW, PJW, ACG, NMF and KH also acknowledge funding from the MRC Centre for Global Infectious Disease Analysis (reference MR/R015600/1), jointly funded by the UK Medical Research Council (MRC) and the UK Foreign, Commonwealth \& Development Office (FCDO), under the MRC/FCDO Concordat agreement and is also part of the EDCTP2 programme supported by the European Union; and acknowledge funding by Community Jameel. GF was also supported by the Jan Wallanders and Tom Hedelius Foundation and the Tore Browaldh Foundation grant No P19-0110. ACG and NMF acknowledge additional support from The Wellcome Trust through a concordat arrangement with FCDO.

We thank for comments on earlier stages of the work and inspirational discussions the ncov modelling team at the MRC Centre for Global Infectious Disease Analysis, Liam Dwyer, Steven Riley, Nimalan Arinaminpathy, Jonathan Haskel, Lord Andrew Tyrie, and David Miles. We thank Sabine van Elsland for managing communications and public relations for this study. Disclaimer: "The views expressed are those of the authors and not necessarily those of the United Kingdom (UK) Department of Health and Social Care, the National Health Service, the National Institute for Health Research (NIHR), Public Health England (PHE), or of the commentators".

\section{Author contributions}

DH, PCS, KH, GF and PC conceived and designed the work; DH undertook and KH, PCS, GF, PC and SB contributed to the analysis and interpretation of data; $\mathrm{DH}$ created new software used in the work; $\mathrm{KH}$ wrote the first draft of the paper and PCS, DH and GF substantially revised it; SB, ABH, PW, MM, ACG, PW and NMF contributed to interpretation of the data and substantially revised the paper. All authors have approved the submitted version and have agreed to be personally accountable for the author's own contributions and to ensure that questions related to the accuracy or integrity of any part of the work, even ones in which the author was not personally involved, are appropriately investigated, resolved, and the resolution documented in the literature.

\section{Data availability and computer code}

All data used in this study are publicly available, and references are provided in the method sections of the main manuscript or the supplement.

The computer code is available on GitHub.

\section{References}

1 Auger, K. A., Shah, S. S., Richardson, T., ... \& Thomson, J. E. Association Between Statewide School Closure and COVID-19 Incidence and Mortality in the US. JAMA 324, 859-870, doi:10.1001/jama.2020.14348 (2020).

2 Edmunds, W. J. Finding a path to reopen schools during the COVID-19 pandemic. The Lancet Child \& Adolescent Health, doi:10.1016/S23524642(20)30249-2 (2020).

3 UNESCO. (ed UNESCO Institute for Statistics data) (United Nations Educational, Scientific and Cultural Organization, 2020).

4 Lempel, H., Epstein, J. M. \& Hammond, R. A. Economic cost and health care workforce effects of school closures in the U.S. PLoS Curr 1, RRN1051RRN1051, doi:10.1371/currents.rrn1051 (2009).

5 Burgess, S. \& Sievertsen, H. The long-term consequences of missing a term of school (Institute of Labor Economics, 2020).

6 Ilzetzki, E. The economic cost of UK school closures, <https://voxeu.org/article/economic-cost-uk-school-closures> (2020).

7 Azevedo, J. P., Hasan, A., Goldemberg, D., Iqbal, S. A. \& Geven, K. Simulating the potential impacts of CoVID-19 school closures on schooling and learning outcomes: A set of global estimates. (The World Bank, 2020).

8 DELVE. Balancing the Risks of Pupils Returning to Schools, <https://rs-delve.github.io/reports/2020/07/24/balancing-the-risk-of-pupils-returning-toschools.html> (2020).

9 Chen, W.-C., Huang, A. S., Chuang, J.-H., Chiu, C.-C. \& Kuo, H.-S. Social and economic impact of school closure resulting from pandemic influenza A/H1N1. Journal of Infection 62, 200-203, doi:https://doi.org/10.1016/j.jinf.2011.01.007 (2011).

10 WHO. Considerations for school-related public health measures in the context of COVID-19: Annex to Considerations in adjusting public health and social measures in the context of COVID-19 (World Health Organization,, Geneva, Switzerland, 2020).

11 Panovska-Griffiths, J., Kerr, C. C., Stuart, R. M., ... \& Bonell, C. Determining the optimal strategy for reopening schools, the impact of test and trace interventions, and the risk of occurrence of a second COVID-19 epidemic wave in the UK: a modelling study. The Lancet Child \& Adolescent Health, doi:10.1016/S2352-4642(20)30250-9 (2020). 
13 House of Commons. Commons Chamber Volume 685: debated on Wednesday 9 December 2020, <https://hansard.parliament.uk/Commons/2020-1209/debates/B62126B2-4224-4830-9347-4174775A88E7/Engagements> (2020).

14 IMF. Vol. June 2020 (International Monetary Fund,, Washington (DC), 2020).

15 Mandel, A. \& Veetil, V. P. The economic cost of covid lockdowns: An out-of-equilibrium analysis. Available at SSRN 3588421 (2020).

16 Coibion, O., Gorodnichenko, Y. \& Weber, M. The cost of the covid-19 crisis: Lockdowns, macroeconomic expectations, and consumer spending. Report No. 0898-2937, (National Bureau of Economic Research, 2020).

17 Tenreyro, S. Covid 19 and the economy: what are the lessons so far? - speech by Silvana Tenreyro (Bank of England, London, 2020).

18 Schreyer, P. Towards measuring the volume output of education and health services: A handbook. (2010).

19 Pichler, A., Pangallo, M., del Rio-Chanona, R. M., Lafond, F. \& Farmer, J. D. Production networks and epidemic spreading: How to restart the UK economy? (2020).

20 Cakmakli, C., Demiralp, S., Kalemli-Özcan, S., Yesiltas, S. \& Yıldırım, M. A. COVID-19 and Emerging Markets: An Epidemiological Model with International Production Networks and Capital Flows (Catalogue No. WP/20/133, International Monetary Fund, 2020).

21 ONS. UK input-output analytical tables,

<https://www.ons.gov.uk/economy/nationalaccounts/supplyandusetables/datasets/ukinputoutputanalyticaltablesdetailed> (2020).

22 ONS. Industry by occupation in the UK, January to December 2019,

<https://www.ons.gov.uk/employmentandlabourmarket/peopleinwork/employmentandemployeetypes/adhocs/11875industrybyoccupationintheukjanuarytod (2020).

23 ONS. Business Impact of COVID-19 Survey (BICS) results,

<https://www.ons.gov.uk/economy/economicoutputandproductivity/output/datasets/businessimpactofcovid19surveybicsresults> (2020).

24 Kilic, K. \& Marin, D. How COVID-19 is transforming the world economy, <https://voxeu.org/article/how-covid-19-transforming-world-economy> (2020).

25 Seric, A. \& Winkler, D. COVID-19 could spur automation and reverse globalisation - to some extent, <https://voxeu.org/article/covid-19-could-spurautomation-and-reverse-globalisation-some-extent> (2020).

26 NHS England. COVID-19 Hospital Activity, 2020).

27 Diekmann, O., Heesterbeek, J. A. P. \& Roberts, M. G. The construction of next-generation matrices for compartmental epidemic models. Journal of The Royal Society Interface 7, 873-885, doi:doi:10.1098/rsif.2009.0386 (2010).

28 Béraud, G., Kazmercziak, S., Beutels, P., ... \& Dervaux, B. The French Connection: The First Large Population-Based Contact Survey in France Relevant for the Spread of Infectious Diseases. PLOS ONE 10, e0133203, doi:10.1371/journal.pone.0133203 (2015).

29 Volz, E., Mishra, S., Chand, M., ... \& Ferguson, N. M. (ed MRC Centre for Global Infectious Disease Analysis) (MRC GIDA, London, 2020).

$30 \mathrm{Xu}, \mathrm{Y} ., \mathrm{Li}, \mathrm{X}$., Zhu, B., ... \& Shen, J. Characteristics of pediatric SARS-CoV-2 infection and potential evidence for persistent fecal viral shedding. Nature medicine 26, 502-505 (2020).

31 Lavezzo, E., Franchin, E., Ciavarella, C., ... \& Navarin, N. Suppression of a SARS-CoV-2 outbreak in the Italian municipality of Vo'. Nature 584, 425-429 (2020).

32 Gudbjartsson, D. F., Helgason, A., Jonsson, H., ... \& Agustsdottir, A. B. Spread of SARS-CoV-2 in the Icelandic population. New England Journal of Medicine 382, 2302-2315 (2020).

$33 \mathrm{Bi}$, Q. et al. Epidemiology and transmission of COVID-19 in 391 cases and 1286 of their close contacts in Shenzhen, China: a retrospective cohort study. The Lancet Infectious Diseases 20, 911-919 (2020).

34 Liu, T., Liang, W., Zhong, H., ... \& Li, J. Risk factors associated with COVID-19 infection: a retrospective cohort study based on contacts tracing. Emerging microbes \& infections $9,1546-1553$ (2020).

35 Baqaee, D., Farhi, E., Mina, M. J. \& Stock, J. H. Reopening Scenarios (Catalogue No. 27244, The National Bureau of Economic Research, Cambridge, MA, 2020).

36 Azzimonti, M., Fogli, A., Perri, F. \& Ponder, M. Pandemic control in econ-epi networks (National Bureau of Economic Research, 2020).

37 Alvarez, F. E., Argente, D. \& Lippi, F. A simple planning problem for covid-19 lockdown. Report No. 0898-2937, (National Bureau of Economic Research, 2020). 
ONS. Which occupations have the highest potential exposure to the coronavirus (COVID-19)?,

$<$ https://www.ons.gov.uk/employmentandlabourmarket/peopleinwork/employmentandemployeetypes/articles/whichoccupationshavethehighestpotentialexpc 05-11> (2020).

41 Budish, E. B. R< 1 as an Economic Constraint: Can We'Expand the Frontier'in the Fight Against Covid-19? University of Chicago, Becker Friedman Institute for Economics Working Paper(2020).

\section{Figures}
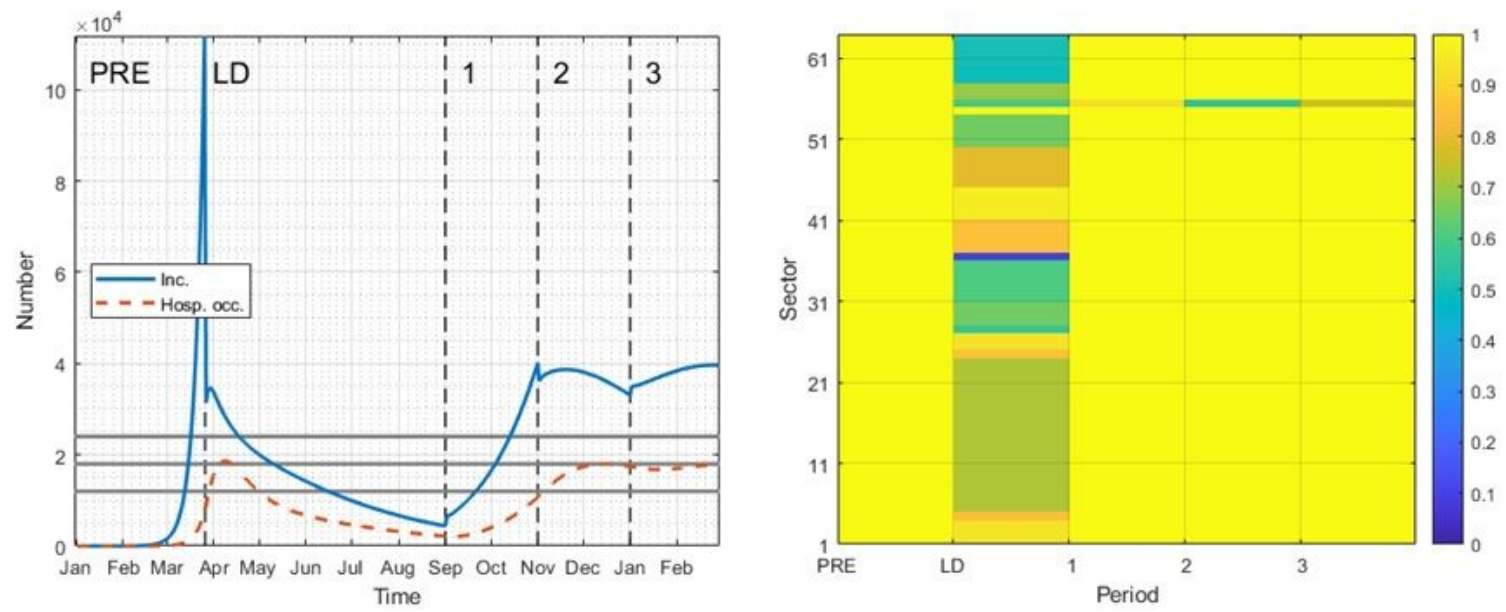

\section{Figure 1}

Optimal economic configuration under scenario A (GDP maximization), hospital capacity 18,000 beds, January 2020 to February 2021 . (A) Projected incidence and hospital occupancy (B) Economic configuration across 63 sectors. Scenario A maximizes GDP via successive bi-monthly opening and closing of 63 sectors over a six-months intervention period, subject to epidemiological and economic constraints; any economic sector including education may close to $80 \%$ of observed minimum levels during the UK's first lockdown (March-May 2020), but not lower, in order to sustain essential services; (A) shows projected daily infection incidence and daily hospital occupancy from January 2020 to February 2021; emergency hospital capacity for the treatment of COVID-19 patients is constrained at 18,000 beds (2nd grey line from below); (B) illustrates the optimal economic configurations (extent of bi-monthly sector closures) under Scenario A GDP maximization; sector divisions are listed on the vertical axis (see table S4 for sector descriptions), and months on the horizontal axis; PRE is the pre-pandemic period, LD is the first lockdown March-May 2020 in the UK, based on available data for closures of higher-level sector categories; period 1 is September-October 2020, period 2 is November-December 2020, period 3 is January-February 2021; openings vary between fully open as prepandemic (yellow, 1) to closed (blue, 0); scenario recommends partial closure of education sector (See table S3).
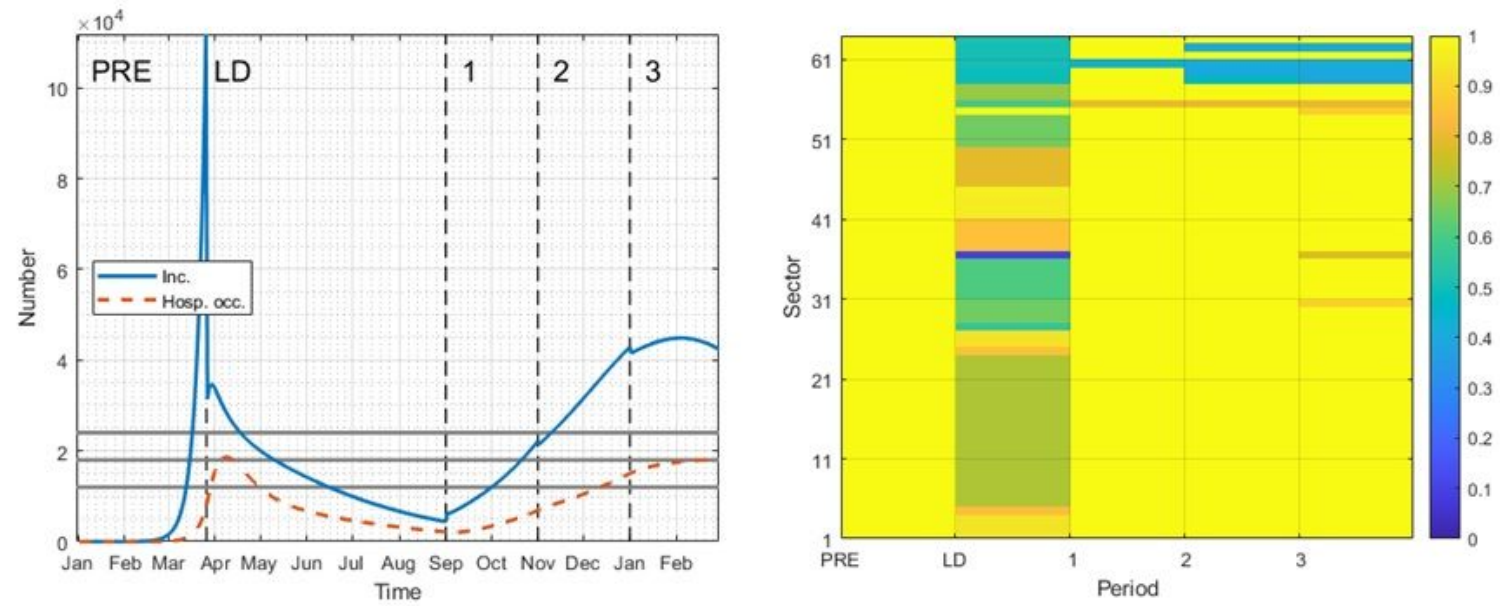

Figure 2 
Optimal economic configuration under scenario A (education open), hospital capacity 18,000 beds, January 2020 to February 2021 . (A) Projected incidence and hospital occupancy (B) Economic configuration across 63 sectors. Scenario B optimizes GDP via successive bi-monthly opening and closing of 63 sectors over a six-months intervention period, subject to epidemiological and economic constraints; any economic sector except for education may close to $80 \%$ of observed minimum levels; education is constrained to operational at or above $80 \%$ of pre-pandemic production levels; (B) optimal economic configuration targets several sectors for partial closure (see table S4).
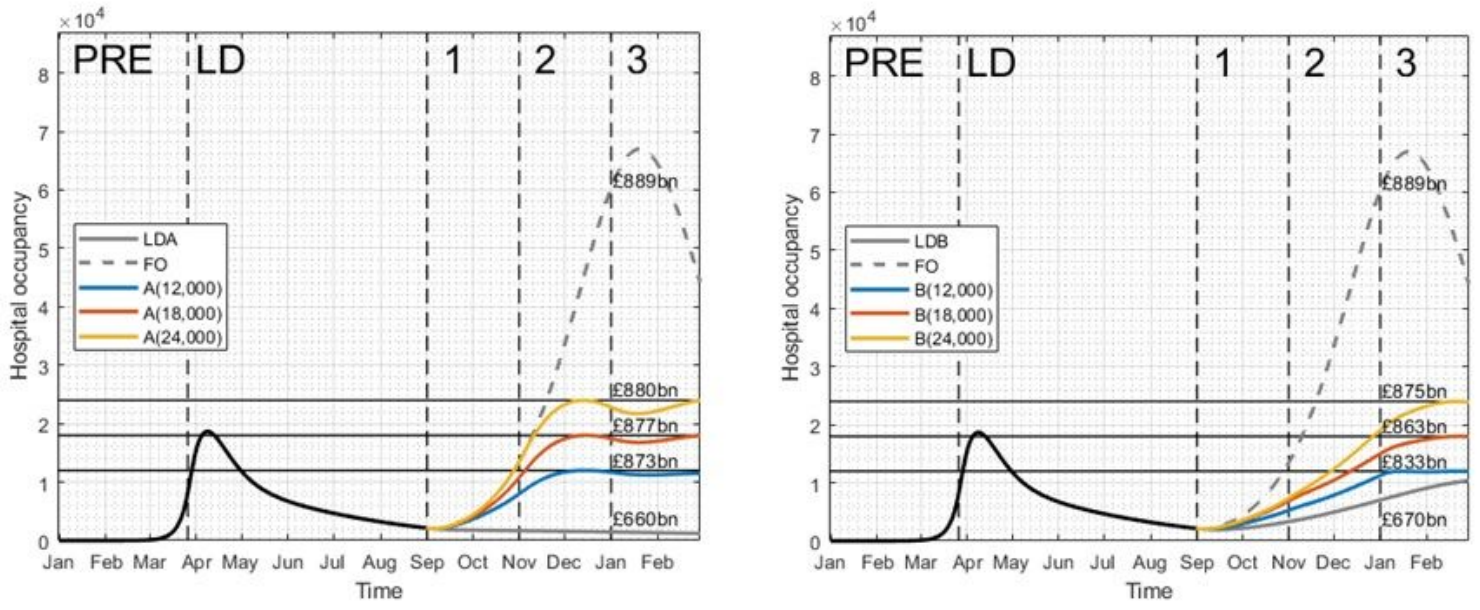

\section{Figure 3}

Projected hospital occupancy and GDP for all scenarios and hospital capacity constraints, January 2020 to February 2021. (A) Scenarios A (GDP maximization), LDA, FO; (B) Scenarios B (education open), LDB, FO. In scenario FO, all sectors are open at pre-pandemic levels; in all scenarios including FO, stringent NPIs and self-protective behavior reduce transmission; three grey horizontal lines represent alternative Hmax; aggregate GDP over six months; (A) Scenarios A: any economic sector -including education - may close to $80 \%$ of observed minimum levels; LDA: all economic sectors close to observed minima. (B) Scenarios B: education sector is operational at $80 \%$ throughout and all other sectors may close to observed minima; LDB: all economic sectors close to observed minima except for the education sector which is operational at $80 \%$.

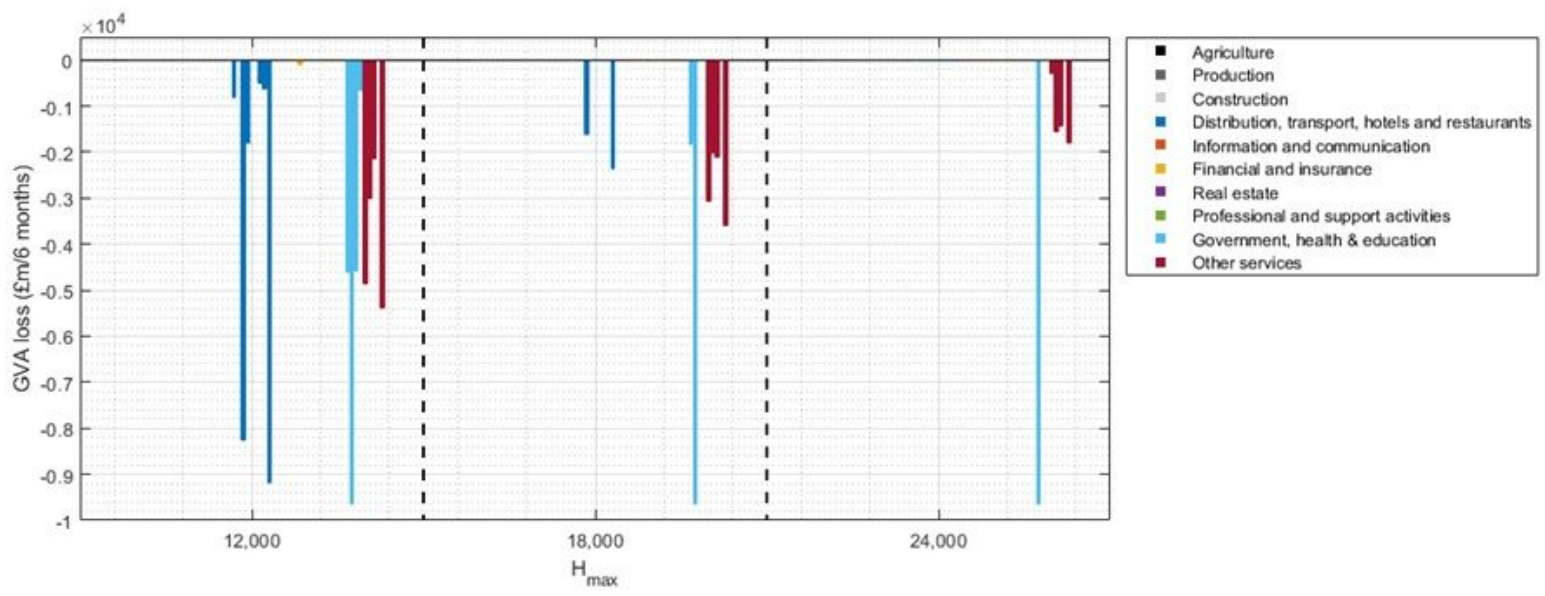

Figure 4

Loss in Gross Value Added under scenario B (education open), September 2020 to February 2021. Gross Value Added (GVA) aggregate loss over six months for sectors selected for partial closure by Scenario B, compared to FO (fully open, see table S5), under three assumptions on Hmax. Hmax=12,000: Dark blue sectors from 'Distribution, transport, hotels and restaurants' from left to right are 28 'Wholesale and retail trade and repair of motor vehicles and motorcycles', 30 'Retail trade, except of motor vehicles and motorcycles' (loss of £8.3bn), 31 'Land transport and transport via pipelines', 34 'Warehousing and support activities for transportation', 35 'Postal and courier activities', 36 'Accommodation and food service activities' (loss of £9.2bn); light blue sectors from 'Government, health \& education' from left to right are 55 'Public administration and defence; compulsory social security', 56 'Education' (loss of $£ 9.7 \mathrm{bn}$ ), 57 'Human health activities', 58 'Social work activities'; dark red sectors from 'Other services' from left to right are 59 'Creative, arts and entertainment activities; libraries, archives, museums and other cultural activities, gambling and betting activities', 60 'Sports activities and amusement and recreation activities', 61 'Activities of membership organisations', 63 'Other personal service activities'. Hmax=18,000: dark blue sectors from 'Distribution, transport, hotels and restaurants' from left to right are 30 'Retail trade, except of motor vehicles and motorcycles', 36 'Accommodation and food service activities'; light blue sectors from 'Government, health \& education' from left to right are 55 'Public administration and defence; compulsory social security', 56 'Education' (loss of $£ 9.7 \mathrm{bn}$ ); dark red sectors from 'Other services' from left to right are 59 'Creative, arts and entertainment activities; libraries, archives, museums and other cultural activities; gambling and betting activities', 60 'Sports activities and amusement and recreation activities', 61 'Activities of membership organisations' 63 'Other 
personal service activities'. Hmax=24,000: light blue sector from 'Government, health \& education' from left to right is 56 'Education' (loss of $£ 9.7 \mathrm{bn}$ ); dark red sectors from 'Other services' from left to right are 59 'Creative, arts and entertainment activities; libraries, archives, museums and other cultural activities; gambling and betting activities', 60 'Sports activities and amusement and recreation activities', 61 'Activities of membership organisations' 63 'Other personal service activities'.

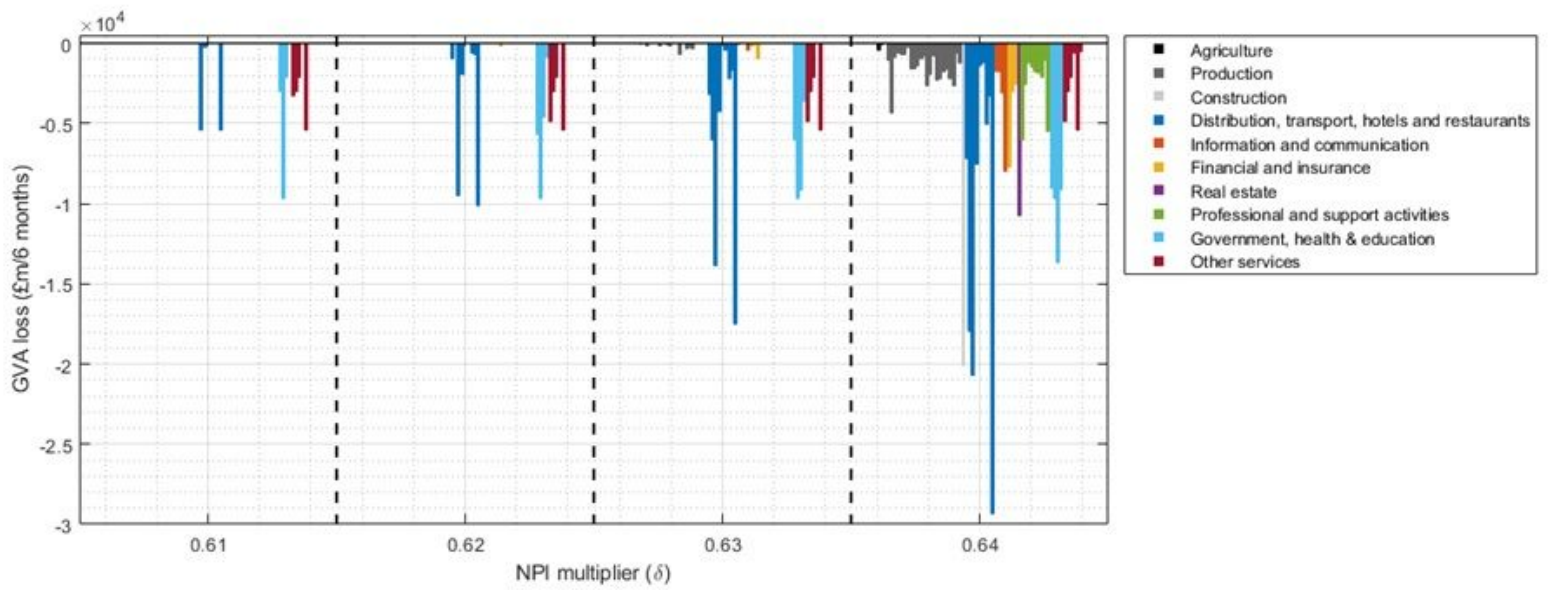

Figure 5

Alternative assumptions on stringency of other non-pharmaceutical interventions, Scenario B, September 2020 to February 2021 . Aggregate GVA loss over six months of the sectors selected for closure by Scenario B (compared to FO) under alternative assumptions on the stringency of other NPIs and adherence from stronger $(\delta=0.61)$ to weaker $(\delta=0.64)$; calibrated value of $\delta$ for the first lockdown period is 0.54 . Sectors with aggregate GVA loss above $£ 5$ bn over 6 months are: $\delta=0.61$ (relatively stringent NPIs): Dark blue sectors from 'Distribution, transport, hotels and restaurants' from left to right are 30 'Retail trade, except of motor vehicles and motorcycles', and 36 'Accommodation and food service activities'; light blue sector from 'Government, health \& education' is 56 'Education'; dark red sector from 'Other services' is 63 'Other personal service activities'. $\delta=0.62$ : Dark blue sectors from 'Distribution, transport, hotels and restaurants' are 30 'Retail trade, except of motor vehicles and motorcycles', and 36 'Accommodation and food service activities'; light blue sectors from 'Government, health \& education' are 55 'Public administration and defence; compulsory social security', 56 'Education', and 57 'Human health activities'; dark red sectors from 'Other services' are 59 'Creative, arts and entertainment activities; libraries, archives, museums and other cultural activities; gambling and betting activities', and 63 'Other personal service activities'. $\delta=0.63$ : Dark blue sectors from 'Distribution, transport, hotels and restaurants' are 29 'Wholesale trade, except of motor vehicles and motorcycles', 30 'Retail trade, except of motor vehicles and motorcycles' (high loss of nearly £14bn), and 36 'Accommodation and food service activities' (high loss of nearly $£ 16 \mathrm{bn}$ ); light blue sectors from 'Government, health \& education' are 55 'Public administration and defence; compulsory social security', 56 'Education', and 57 'Human health activities' (high loss of over $£ 12 \mathrm{bn}$ ); dark red sectors from 'Other services' are ' 59 Creative, arts and entertainment activities; libraries, archives, museums and other cultural activities; gambling and betting activities', and 63 'Other personal service activities'. $\delta=0.64$ (relatively weak NPIs): Light grey sector is 'Construction'; dark blue sectors from 'Distribution, transport, hotels and restaurants' are 28 'Wholesale and retail trade and repair of motor vehicles and motorcycles', 29 'Wholesale trade, except of motor vehicles and motorcycles' (high loss of $£ 12 \mathrm{bn}$ ), 30 'Retail trade, except of motor vehicles and motorcycles' (high GVA loss of nearly £21 bn), 31 'Land transport and transport via pipelines', and 36 'Accommodation and food services' (high GVA loss of over $£ 26 \mathrm{bn}$ ); orange sector from 'Information and communication' is 40 'Computer programming, consultancy and related activities; information service activities; yellow sector from 'Financial and insurance' is 41 'Financial service activities, except insurance and pension funding'; purple sector is 44 'Real estate activities'; dark green sectors are 46 'Legal and accounting activities; activities of head offices; management consultancy activities', and 54 'Security and investigation activities; services to buildings and landscape activities; office administrative, office support and other business support activities'; light blue sectors from 'Government, health \& education' are 55 'Public administration and defence; compulsory social security', 56 'Education', and 57 'Human health activities' and 58 'Social work activites'; dark red sectors from 'Other services' are 59 'Creative, arts and entertainment activities; libraries, archives, museums and other cultural activities; gambling and betting activities', and 63 'Other personal service activities'.

\section{Supplementary Files}

This is a list of supplementary files associated with this preprint. Click to download.

- educationpapersupplforNaturecomp.docx 